\title{
Clinical Trial Stakeholder Communication Plan
}

National Cancer Institute

\section{Source}

National Cancer Institute. Clinical Trial Stakeholder Communication Plan. NCI Thesaurus. Code C115783.

A proposed method to describe the communication strategy between stakeholders of a clinical trial. 